\title{
A health promoting schools approach to bullying
}

PENNI CUSHMAN AND TRACY CLELLAND

\section{KEY POINTS}

- Schools use a wide range of strategies to address bullying behaviour and relationship issues, but only a few schools in the survey reported in this article had a comprehensive approach to being health promoting schools.

- A proactive approach would involve schools providing all students with opportunities to develop the skills and understandings necessary to build strong relationships and resilience.

- $\quad$ The three-pronged approach of curriculum teaching and learning, school organisation and ethos, and community links and partnerships are the essential components for success as a health promoting school. 


\section{Media headlines ensure that we are constantly reminded of the presence of bullying in our schools. This article draws on responses to a national survey on barriers to student learning. The strategies that primary and secondary schools that responded are implementing to address bullying are discussed in relation to the approach known as "health promoting schools" - an approach that is internationally recognised for its effectiveness in addressing mental health issues in schools.}

It is impossible to determine the exact number of bullying incidents that occur in our primary and secondary schools each year. While there is some evidence to suggest that students now find schools safer places than they were 10 years ago (CarrollLind, 2009), media focus on some of the more serious bullying ensures that we remain mindful that these behaviours still confront students. Between January 2010 and the beginning of May 2011, almost 400 articles related to bullying in schools appeared in New Zealand's major metropolitan newspapers. Headlines such as "Bullying Taking Toll in Schools" (2010), "Girls Get Down and Dirty" (2011) and "Bashed Teenager Fears Returning to School” (Binning, 2011) indicate the extent and seriousness of the problem.

Bullying is most commonly defined by three characteristics: it is intentionally harmful, it is repetitive in nature and there is a power differential between the aggressor and victim (Olweus, 1993). While some of the media reports appear to be discussing behaviour that could represent other forms of aggression, such as assault, rather than bullying, they do suggest that there is a heightened awareness of bullying behaviours, and a greater likelihood that they will be reported than in the past. Information and communication technologies (ICTs) are allowing incidents to be viewed not just locally but also globally. Instances of bullying conducted, for example, through texting and Internet communication have led to the recording and sharing of bullying incidents that might previously have gone unnoticed by anyone other than the participants and immediate witnesses.

In this article, we report on bullying as a barrier to learning, and on the strategies schools are using to address bullying. The findings are drawn from a national survey we conducted on the health issues that affect student learning in schools. Our particular aim in presenting these findings is to consider if the approach known as "health promoting schools"- which has been found to be effective internationally for addressing mental health issues in schools_-is being used in New Zealand to create a climate that helps limit bullying behaviours.

\section{Bullying: How bad is it?}

The extent, complexity and repercussions of bullying in New Zealand schools have been well researched and reported by Carroll-Lind (2009) in her comprehensive enquiry into the safety of students at school. During her enquiry, which she completed under the auspices of New Zealand's Office of the Children's Commissioner, Carroll-Lind conducted interviews with primary and secondary school students, parents, counsellors, teachers and organisations involved with young people's welfare. Although schools are legally required to provide a safe physical and emotional environment for students — see the Ministry of Education's National Administration Guideline 5(i) (Ministry of Education, 2010)_Carroll-Lind found many young people did not feel safe at school.

A cross-national study conducted by the International Association for the Evaluation of Educational Achievement (Martin, Mullis, \& Foy, 2008) revealed high levels of bullying in New Zealand primary schools compared to schools in other countries, with rates more than 50 percent above the international average. Furthermore, in their national survey of New Zealand 9- to 13-yearolds, Carroll-Lind, Chapman and Raskauskas (2008) found 72 percent of the students stated they had witnessed or experienced "some" to "a lot" of bullying incidents in their schools. The surveyed students gave bullying as the main reason for not liking school.

Findings are not clear cut, however. The Youth '07 study on the health and wellbeing of more 
than 9,000 secondary school students (Adolescent Health Research Group, 2008) found that, similar to international data, 6 percent of students reported they were bullied once a week or more and 10 percent were afraid that someone would hurt or bother them. The study also found that, while there was a wide variation between schools, overall, students felt safer in, and more connected with, their schools than in 2001.

A healthy and positive school environment is important for students' achievement and their wellbeing (Adolescent Health Research Group, 2008). Dislike of school is not the only effect that bullying has on students. Coggan, Bennett, Hooper and Dickinson (2003), for example, linked bullying to anxiety, depression and poor overall mental health for victims. Similarly, the Youth '07 study (Adolescent Health Research Group, 2008) found students who had been bullied were about five times as likely to have significant depressive symptoms or three times as likely to have attempted suicide as students who had not been bullied. The relationship between students' wellbeing and their ability to achieve academically is evident in both primary and secondary schools: students with poor mental health are likely to have low levels of academic achievement (see, for example, Australian Catholic University, 2008; Stafford, Moore, Foggett, Kemp, \& Hazell, 2007). Not surprisingly, mentally healthy students (i.e., those who have a positive sense of self-worth and who demonstrate social competence) are better learners, have better relationships with their teachers and display more resilience in meeting challenges (International Union for Health Promotion and Education, 2009).

An Australian study conducted in 600 schools found that students with higher scores on scales of connectedness to their school and who reported a positive school climate also had higher average scores on reading comprehension and mathematics achievement scales (Rothman \& McMillan, 2003). In her review of international literature relating to health promoting schools conducted for the New Zealand Ministry of Health, Dickinson (2005) concluded that young people experience more positive learning and achievement outcomes when they experience school as a caring and supportive social and learning environment.

Stafford et al. (2007), among other commentators, argue that an integral part of quality teaching - and therefore the business of schools - must be the pursuit of student wellbeing and the provision of supportive environments. The New Zealand Curriculum (Ministry of Education, 2007) acknowledges the importance of Health and Physical Education in this regard: “... this learning area makes a significant contribution to the well-being of students beyond the classroom, particularly when it is supported by school policies and procedures
... mentally healthy students (i.e., those who have a positive sense of self-worth and who demonstrate social competence) are better learners, have better relationships with their teachers and display more resilience in meeting challenges

and by the actions of all people in the school community" (p. 22).

Although the climate of New Zealand schools does not always appear to be conducive to sound mental health (Carroll-Lind, 2009), it is important to emphasise that schools alone cannot shoulder the blame or responsibility for creating and addressing mental health issues that are barriers to learning. As McCreanor, Watson and Denny (2006, p. 156) state, families "remain a crucial site for interventions to enhance the wellbeing of young people". Research by Hornby and Witte (2010) found that parental involvement in schools, in particular where school and home worked collaboratively, had the potential to improve students' academic achievement and social outcomes.

Vreeman and Carroll's (2007) comprehensive review of literature on school-based interventions to reduce bullying found evidence that such incidents could be reduced by well-planned systematic interventions. Of particular significance is their finding that curriculum interventions alone do not consistently decrease bullying. Bullying behaviour is now conceptualised as a systemic phenomenon (Vreeman \& Carroll, 2007) influenced by a wide range of risk and protective factors that relate to: the individual; family and peers; school environments; and community, cultural norms and media. As such, it needs a systemic solution.

\section{Health promoting schools}

The approach known as "health promoting schools" is one such systemic solution. Over the past 20 or so years, the potential that this approach has for addressing barriers to learning through the development of positive and supportive school environments has received increasing international attention. The approach is described differently in various documents but most descriptions comprise some combination of the elements inherent in the World Health Organisation's broad definition (World Health Organisation, 1996, p. 2): 
A health promoting school is one in which all members of the school community work together to provide pupils with integrated and positive experiences and structures, which promote and protect their health. This includes both the formal and the informal curriculum in health, the creation of a safe and healthy school environment, the provision of appropriate health services and the involvement of the family and wider community in efforts to promote health.

As Smith, Schneider, Smith and Ananiadou (2004) note, such whole-school approaches have multiple components that operate simultaneously at different levels in the school context. Interestingly, one of the first examples of a health promoting schools approach being implemented was the Olweus Bullying Prevention Programme in Sweden (Olweus, 1993).

One of the key aims of the health promoting schools approach is to align the many different layers or aspects of school practice so that they are all health promoting and reinforcing each other. The health promoting schools framework $^{1}$ (see Figure 1) ensures that change is coordinated through the curriculum, the social and physical environments of the school, the involvement of parents and health agencies and associated policy development.

FIGURE 1 THE HEALTH PROMOTING SCHOOLS FRAMEWORK

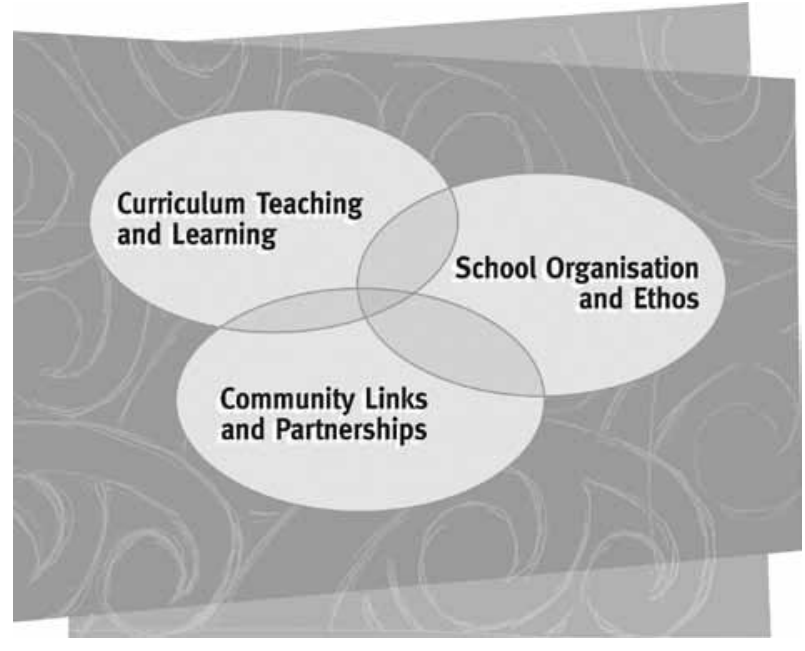

Source: Ministry of Health (2007)

According to St Leger, Kolbe, Lee, McCalle and Young (2007), the health promoting schools approach is the most effective way of exerting a positive influence on students' health-related behaviours and academic outcomes. Although not all recent literature syntheses have found whole-school approaches to bullying effective (Swearer, Espelage, Vaillancourt, \& Hymel, 2010), Smith et al. (2004) and Vreeman and Carroll (2007) show the whole-school or health promoting schools approach to be more successful than approaches that have relied on only one or two interventions, such as a classroom programme.
It is important to note that while the health promoting schools and the whole-school approach tend to be seen as synonymous, the health promoting schools approach places a greater emphasis on including the community beyond the school gates, thereby ensuring collaboration with parents and relevant community services and organisations. According to Buijs (2009), programmes promoting mental health that are developed and implemented in accordance with the health promoting schools approach are particularly effective when they: include changes to the school culture; involve students, teachers and parents; focus on developing personal skills and resilience; and are implemented over a long period. Carroll-Lind (2009) agrees, emphasising that altering the school environment to build a strong school and community culture requires students, teachers and parents to share responsibility for bringing about these changes and "developing positive school climates that discourage bullying and encourage students to care about each other" (p. xi). In a later work entitled Responsive Schools, Carroll-Lind (2010) describes the various possible components of health promoting schools and presents case studies of schools in which these elements have been successfully implemented.

Cushman (2008), overviewing the state of the health promoting schools movement in New Zealand, found that not many schools had fully integrated this approach. Mohammadi, Rowling and Nutbeam (2010) suggest that many school staff find the concept of health promoting schools obscure and so tend not to use it at all or to interpret it in many ways.

In 2010, we set out to explore, through a nationwide survey, New Zealand teachers' understanding of health promoting schools and their awareness of the relationship between the elements of this approach and educational outcomes. We also sought to explore teachers' perceptions of the health issues that had an effect on students' learning and to report the strategies that respondents said their schools had in place to address these matters. Bullying was one of the issues raised by survey respondents.

\section{Method}

We randomly selected 1,000 New Zealand primary and secondary schools for potential participation in the survey. The questionnaire included eight questions that asked the respondents to identify health issues affecting learning in their schools and what their schools were doing to address those issues. Respondents were also asked to state their understanding of health promoting schools. The data that we present and discuss in this article are based on responses to three of these questions:

1. In your school, are you aware of health issues impacting on students' learning? If yes, please list below. 
2. Do you have strategies in place to address these issues?

(A text box was provided with the heading Health Issues on the left-hand side and Strategies Currently in Place on the right-hand side.)

3. Do you see a relationship between "health promoting schools" and educational outcomes? (The three-point response scale provided was yes, not sure, no.)

The simple preliminary analyses presented in this article drew on the responses we received by the end of June 2010. Two members of our research team independently and then collaboratively coded and analysed the qualitative data according to the emerging themes.

\section{Results and discussion}

Three hundred and eighteen schools (32 percent of the total sample) returned the survey. Three hundred identified health issues that they considered influenced learning. We note that because survey respondents represented only 12 percent of schools, the findings reflect the views of this sample rather than the entire school population. However, the findings do provide some useful insight into the strategies this sample is implementing to address one perceived barrier to learning, namely bullying.

In response to the question, "Do you see a relationship between health promoting schools and educational outcomes?" 89 percent of the respondents said, "Yes", 11 percent said they were "Not sure" and less than 1 percent said "No".

Given the findings of Stewart, Parker and Gillespie (2000) and Mohammadi et al. (2010) that school staff found the health promoting schools concept obscure, it must be noted that it is possible that respondents were responding to the general concept of health promotion and not the health promoting approach as depicted in Figure 1. However, another question asked in the survey ("What is your understanding of a 'health promoting school'?") provides some indication of the extent of understanding. Ninety-nine respondents specifically mentioned the three dimensions depicted in Figure 1. Other respondents provided responses indicating differing interpretations and levels of understanding. Some of these suggested the respondents might have had a good understanding through their use of terms such as whole-school approach but further detail or examples of the three dimensions was missing. Others simply referred to classroom programmes, suggesting a lack of understanding.

\section{Reports of bullying}

Of interest is the fact that, despite the high media profile afforded to bullying, only 11 percent of the surveyed schools referred specifically to this behaviour.

\section{While there was almost no difference between urban and rural schools, secondary schools identified bullying to a far greater extent than did primary schools.}

Bullying was more likely to be identified as an issue in high-decile and mid-decile schools than in low-decile schools (13 percent of high-decile schools compared to 6 percent of low-decile schools). While there was almost no difference between urban and rural schools, secondary schools identified bullying to a far greater extent than did primary schools. Moreover, the comment by one secondary school respondent of "usual teenage issues-bullying", suggests that school staff might view bullying as an expected form of behaviour among this age group. Given that a further 11 percent of schools identified "relationships with others" as an issue, it is tenable that respondents might have included bullying in this category. As was the case with concerns related to bullying, relationships presented as slightly more of an issue in high-decile than in low-decile settings. Relationship issues presented in much greater numbers in secondary schools than in primary and intermediate, but varied little between urban and rural environments. While the reasons for these differences between primary and secondary, rural and urban, and high and low decile are unclear and beyond the scope of this article, further investigation is warranted to confirm the trends and find reasons for them.

\section{Strategies used to address issues}

Every school that referred to bullying (and relationship issues) as adversely affecting learning provided a list of strategies that their schools had implemented. Classroom programmes related to mental health and wellbeing were the most commonly mentioned strategy but were mentioned by fewer than half of the schools. Specific topics included relationship skills, coping strategies, assertiveness skills and conflict resolution. Some schools mentioned the use of specific programmes such as Kia Kaha, Keeping Ourselves Safe, Cool Schools and Circle Time. Supporting evidence that classroom programmes by themselves are largely ineffective (Vreeman \& Carroll, 2007), schools provided evidence of their understanding that they needed to operate within the context of a supportive whole-school environment. Although only 9 percent of schools specifically referred 
to the importance of a positive and nurturing school culture, another 18 percent of respondents referred to essential factors in a school environment, such as staff role modelling of positive behaviours, professional development of staff and supportive school policies.

Other school-wide strategies, one or more of which were mentioned by nearly all respondents, included the use of school assemblies to acknowledge and affirm positive relationship skills, "bully boxes" for anonymous posting of bullying incidents, friendship stops where students could find a buddy to play with, bullying audits, the provision of extracurricular opportunities so students could share time with others with like interests and "safe rooms". One school described their safe room as a place where students "could initiate time-out in a homely, safe atmosphere with music". Several respondents also referred to the use of restorative practices in their schools, thereby acknowledging the growing popularity of these relatively newer approaches to addressing bullying and relationship issues. It appears that in using such strategies, most of the schools recognised, to a lesser or greater degree, the effect of bullying and emotional issues on both students' academic outcomes and mental health (Carroll-Lind, 2009).

It is worth noting the importance that respondents attributed to counselling provisions for students with bullying and relationship issues. The majority of secondary school respondents reported that their schools had guidance counsellors onsite. Because many New

\section{Other school-wide strategies,} one or more of which were mentioned by nearly all respondents, included the use of school assemblies to acknowledge and affirm positive relationship skills, "bully boxes" for anonymous posting of bullying incidents, friendship stops where students could find a buddy to play with, bullying audits, the provision of extracurricular opportunities so students could share time with others with like interests and "safe rooms".
Zealand primary schools do not have their own full-time counsellor, primary school respondents said their schools tended to refer students to other health professionals, such as social workers, Resource Teachers: Learning and Behaviour (RTLBs) and public health nurses. These professionals are rarely attached to one school, which means that response to incidents is often delayed. Primary schools were also more likely to refer students to social services based in the community, with respondents in a number of the schools noting the importance of close ties with health services.

There was evidence of some understanding of the importance of parental support and education for parents. In some schools, casual forums such as coffee mornings, open-door policies and newsletter articles were being used to informally educate parents on enhancing resilience and managing relationships. When deemed necessary, some schools implemented more formal strategies, such as parent-teacher conferences, parent education, provision of parent counselling and referral to social agencies. Comments by a number of respondents reflected Hornby and Witte's (2010) views on the importance of parents and schools working together. One teacher from a large urban primary school, for example, admitted that her school was "struggling to contain bullying". She saw the value of parent education as the opportunity it gave parents to support the school's efforts to counteract bullying behaviour, not just inside school grounds but also outside. This and various other parent-directed strategies again emphasised schools' recognition that family involvement is crucial to the success of any measure directed toward enhancing the mental wellbeing of young people.

Although the respondents' answers revealed a wide range of strategies being used to address bullying behaviour and relationship issues, only a few schools appeared to have a comprehensive approach to being health promoting schools. Many of those schools with classroom health-related programmes complemented classroom teaching with zero-tolerance attitudes and wider school activities such as peer mediation and restorative practices that enabled students to practise skills they had learnt in the classroom. However, of the schools that reported using both classroom and wider school strategies, few had broadened this approach to include parental partnerships and community links.

The three-pronged approach illustrated in the framework (Figure 1) appears to be essential for success as a health promoting school. For most schools, two of the dimensions were present but rarely three. This suggests that some schools' interpretation of health promoting schools may be more closely aligned to the general concept of promoting health rather than the health promoting schools approach. 
Table 1 sets out the range of strategies, listed under the three components of the health promoting schools approach, that schools between them had implemented to address bullying.

\section{Conclusion}

Carroll-Lind's (2009) comment that "there is now a general recognition that bullying occurs in all schools and it is more important for teachers to gain information on how to deal with bullying when it happens rather than simply collecting more data on prevalence and incidence" (p. 39) has direct relevance for the findings from our survey with respect to bullying and associated relationship issues in schools. The size of the study and the fact that there was not a specific question relating to bullying occurrences and responses obviously limits the validity and reliability of the findings. Nevertheless, 22 percent of respondents, regardless of school type, location and socioeconomic level, considered the presence of issues around bullying and relationships with others had an adverse effect on student learning. Although the survey respondents listed a comprehensive range of strategies to address these issues, they seemed to have implemented them mainly as a response to an issue causing considerable concern rather than as a proactive measure designed to prevent and reduce occurrences.

A more proactive approach, whereby schools provide all of their students with opportunities to develop the skills and understandings necessary to build strong relationships and resilience, needs to underpin any school-based attempt to prevent as well as counteract barriers to learning. The New Zealand Curriculum (Ministry of Education, 2007) states that "students need to be challenged and supported" to develop the key competencies, one of which is relating to others. Furthermore, "mental health", a key area of learning in Health and Physical Education in The New Zealand Curriculum, requires all schools to include in their teaching and learning programmes opportunities for students to develop the knowledge, understanding and skills they need to strengthen personal identity and selfworth, to examine discrimination and stereotyping, to enhance relationships and to recognise and respond to situations of harassment (Ministry of Education, 1999). If all primary and secondary schools allotted sufficient class time to health classes, students would, at the very least, have opportunities to develop skills that would enable them to enhance their relationships with peers. These proactive measures also align well with the Māori

TABLE 1 STRATEGIES SCHOOLS ARE USING TO ADDRESS BULLYING, AS RELATED TO THE THREE COMPONENTS OF THE HEALTH PROMOTING SCHOOLS APPROACH

\begin{tabular}{|c|c|c|}
\hline Component 1: Curriculum teaching and learning & Component 2: School culture and environment & Component 3: School partnerships and services \\
\hline Requires, with respect to students: & $\begin{array}{l}\text { Requires, with respect to staff and the whole- } \\
\text { school environment: }\end{array}$ & $\begin{array}{l}\text { Requires, with respect to students, parents and other } \\
\text { community members: }\end{array}$ \\
\hline $\begin{array}{l}\text { - Strengthening personal identity } \\
\text { - Recognising instances of discrimination } \\
\text { - Acknowledging individual differences } \\
\text { - Respecting others' rights } \\
\text { - Responding constructively to discriminatory } \\
\text { practices and behaviours } \\
\text { - Learning assertiveness skills } \\
\text { - Examining options and consequences and } \\
\text { practising positive responses to challenges } \\
\text { - Having the skills of conflict resolution } \\
\text { - Using a range of communication skills } \\
\text { - Working co-operatively } \\
\text { - Accessing support } \\
\text { - Gaining knowledge of and skills to counter cyber } \\
\text { and text bullying } \\
\text { - Engaging in appropriate homework activities } \\
\text { - Programmes such as: } \\
\text { - Kia Kaha } \\
\text { - Keeping Ourselves Safe } \\
\text { - Circle Time } \\
\text { - Cool Schools (peer mediation) }\end{array}$ & $\begin{array}{l}\text { - Professional development for staff } \\
\text { - Staff role modelling of positive behaviours } \\
\text { - School antibullying policies } \\
\text { - Bullying audits } \\
\text { - Restorative practices } \\
\text { - Policies on mobile phone use at school } \\
\text { - School bus policies } \\
\text { - School counsellors } \\
\text { - School phone line for students to report } \\
\text { incidences by text } \\
\text { - Consequences for bullies } \\
\text { - Peer mediators } \\
\text { - Safe rooms } \\
\text { - Friendship stops } \\
\text { - A range of extracurricular activities } \\
\text { - A range of ongoing cultural activities } \\
\text { - Anonymous "bullying boxes" }\end{array}$ & $\begin{array}{l}\text { - Open-door policies } \\
\text { - High profile for bullying policy } \\
\text { - Walking school buses } \\
\text { - Relationship with community constable } \\
\text { - Visible presence of constable in school } \\
\text { - Professional development for parents on } \\
\text { enhancing resilience, managing relationships } \\
\text { and addressing bullying } \\
\text { - Links with sports teams } \\
\text { - Bullying articles on school website and in } \\
\text { newsletters } \\
\text { - Coffee mornings for parents and other } \\
\text { interested members of the wider school } \\
\text { community }\end{array}$ \\
\hline
\end{tabular}


Potential Approach developed by Te Puni Kōkiri, which focuses more on identifying opportunities and realising potential and less on targeting and remedying deficits (Ministry of Education, 2009).

While some secondary schools in this study used their guidance counsellors to aid distressed students, primary schools often had to rely on less qualified school-based help, as well as community-based resources. The relatively high number of respondents referring to the need for the involvement of outside agencies suggests this is an area where a more co-ordinated and consistent school-based support structure could be useful.

The questions below could be helpful in determining whether school practices reflect the health promoting schools approach in proactively creating a more caring and safe climate that would assist in decreasing bullying behaviours:

- Does curriculum teaching and learning aim to develop knowledge, skills and attitudes conducive to positive and constructive relationships?

- Do the key competencies underpin all teaching and learning? The key competency relating to others specifically states the "ability to listen actively, recognise different points of view, negotiate and share ideas" (Ministry of Education, 2007, p. 12).

- Are students provided with opportunities to develop and practise skills learnt in the classroom in the wider school environment?

- Does the school have policies about behavioural expectations and, in particular, guidance for addressing bullying incidents?

- Are professional development opportunities provided for staff so their understandings and practices in regard to bullying behaviours reflect best practice?

- Do leadership practices model and support the development of a safe and supportive school environment for students and staff?

- Are parents and caregivers provided with information and opportunities that enable them to support and reinforce the same learning?

- Does the school align the many different layers and aspects of school practice so they reflect a strengthsbased, proactive and cohesive health promoting schools approach?

\section{Resource list for teachers}

Boyd, S., \& Barwick, H. (2011). Wellbeing at school: Building a safe and caring school climate that deters bullying. Wellington: New Zealand Council for Educational Research. Available at: http://www.nzcer.org.nz/system/files/wellbeing-at-schoolbooklet.pdf

Carroll-Lind, J. (2009). School safety: An inquiry into the safety of students at school. Wellington: Office of the Children's Commissioner.
Carroll-Lind, J. (2010). Responsive schools. Wellington: Office of the Children's Commissioner.

Education Review Office. (2007, May). Safe schools: Strategies to prevent bullying. Available at: http://www.ero.govt.nz/ National-Reports/Safe-Schools-Strategies-to-PreventBullying-May-2007

Post Primary Teachers Association. (2007, August). School antiviolence tool kit. Wellington: Author. Available at: http:// www.ppta.org.nz/index.php/collective-agreements/health-asafety/1031-violence-bullying

The Ministry of Health's Health Promoting Schools website has information, educational resources, research and case studies. The website is hosted on Te Kete Ipurangi: http://hps.tki.org.nz/

NetSafe is an independent nonprofit organisation that promotes confident, safe and responsible use of online technologies. The NetSafe website is available at: http:// www.netsafe.org.nz/

\section{Acknowledgement}

The authors wish to express their gratitude to the anonymous peer reviewer for their constructive and helpful advice.

\section{References}

Adolescent Health Research Group. (2008). Youth '07: The health and wellbeing of secondary school students in New Zealand: Technical report. Young people and violence. Auckland: The University of Auckland.

Australian Catholic University. (2008). Scoping study into approaches to student wellbeing. Sydney: Author.

Binning, E. (2011, 30 March). Bashed teenager fears returning to school. The New Zealand Herald, p. A4.

Buijs, G. (2009). Better schools through health: Networking for health promoting schools in Europe. European Journal of Education, 44(4), 507-520.

Bullying taking toll in schools. (2010, 22 April). The New Zealand Herald, p. A5.

Carroll-Lind, J. (2009). School safety: An inquiry into the safety of students at school. Wellington: Office of the Children's Commissioner.

Carroll-Lind, J. (2010). Responsive schools. Wellington: Office of the Children's Commissioner.

Carroll-Lind, J., Chapman, J., \& Raskauskas, J. (2008, November). Bullying: The rough and tumble of school life in New Zealand. Paper presented at the New Zealand Association for Research in Education conference, Massey University, Palmerston North.

Coggan, C., Bennett, S., Hooper, R., \& Dickinson, P. (2003). Association between bullying and mental health status in New Zealand adolescents. International Journal of Mental Health Promotion, 5(1), 16-22. 
Cushman, P. (2008). Health promoting schools: A New Zealand perspective. Pastoral Care in Education, 26(4), 231-241.

Dickinson, P. (2005). Health promoting schools: A review of international literature and models of practice. Wellington: Ministry of Health.

Girls get down and dirty. (2011, 20 March). The New Zealand Herald, p. A37.

Hornby, G., \& Witte, C. (2010). A survey of parental involvement in middle schools in New Zealand. Pastoral Care in Education, 28(1), 59-69.

International Union for Health Promotion and Education. (2009). Achieving health promoting schools: Guidelines for promoting health in school. Geneva: Author.

Martin, M. O., Mullis, I. V. S., \& Foy, P. (2008). TIMSS 2007 international science report. Chestnut Hill, MA: International Association for the Evaluation of Educational Achievement (IEA).

McCreanor, T., Watson, P., \& Denny, S. (2006). "Just accept us how we are more": Experiences of young Pākehā with their families in Aotearoa New Zealand. Social Policy Journal of New Zealand, 27, 156-170.

Ministry of Education. (1999). Health and physical education in the New Zealand curriculum. Wellington: Author.

Ministry of Education. (2007). The New Zealand curriculum. Wellington: Learning Media.

Ministry of Education. (2009). Ka hikitia-Managing for success: The Mãori education strategy 2008-2012. Retrieved 16 August 2011, from http://www.minedu.govt.nz/ theMinistry/PolicyAndStrategy/KaHikitia

Ministry of Education. (2010). National administration guidelines (NAGs). Retrieved 7 June 2011, from http://www. minedu.govt.nz/NZeducation/EducationPolicies/Schools

Ministry of Health. (2007). Health promoting school support manual. Wellington: Learning Media.

Mohammadi, N., Rowling, L., \& Nutbeam, D. (2010). Acknowledging educational perspectives on health promoting schools. Health Education, 110, 240-251.

Olweus, D. (1993). Bullying at school: What we know and what we can do. Oxford: Blackwell.

Rothman, S., \& McMillan, J. (2003). Research report 36: Influences on achievement in literacy and numeracy: Longitudinal studies of Australian youth. Camberwell, VIC: Australian Council for Educational Research.

Smith, J., Schneider, B., Smith, P., \& Ananiadou, K. (2004). The effectiveness of whole-school anti-bullying programs: A synthesis of evaluation research. School Psychology Review, 33(4), 547-560.
Stafford, K., Moore, C., Foggett, K., Kemp, E., \& Hazell, T. (2007, November). Proving and improving: Exploring the links between resilience, behaviour and academic outcomes. Paper presented at the Australian Association for Research in Education (AARE) conference, Fremantle, Perth.

Stewart, D., Parker, E., \& Gillespie, G. (2000). An audit of health promoting schools policy documentation. Journal of School Health, 70, 253-255.

St Leger, L., Kolbe, L., Lee, A., McCalle, D., \& Young, I. (2007). School health promotion: Achievements, challenges and priorities. In D. McQueen \& C. Jones (Eds.), Global perspectives on health promotion effectiveness (pp. 107-124). New York: Springer Science \& Business Media.

Swearer, S., Espelage, D., Vaillancourt, T., \& Hymel, S. (2010). What can be done about school bullying? Linking research to educational practice. Educational Researcher, 39, 38. Retrieved 14 August 2011, from http://edr.sagepub.com/ content $/ 39 / 1 / 38$

Vreeman, R., \& Carroll, A. (2007). A systematic review of school-based interventions to prevent bullying. Archives of Pediatrics \& Adolescent Medicine, 161(1), 78-88.

World Health Organisation. (1996). Health promoting schools, Series 5. Regional guidelines: A framework for action. Manila: Author.

\section{Notes}

1 Note that since this research was completed the Ministry of Health has commissioned the development of a new New Zealand health promoting schools national strategic framework.

PENNI CUSHMAN is a senior lecturer in health education in the College of Education at the University of Canterbury. Email: penni.cushmanळcanterbury.ac.nz

TRACY CLELLAND is a senior tutor in health education in the College of Education at the University of Canterbury. Email: tracy.clellandळcanterbury.ac.nz 